\title{
Symposium 2:
}

\section{Consent, competency and ECT: a philosopher's comment}

\author{
Harry Lesser Department of Philosophy, University of Manchester
}

\section{Editor's note}

Dr Lesser, an English philosopher, while agreeing that competent but irrational decisions to refuse beneficial treatment ought to be overruled, argues that there has to be evidence additional to the mere existence of depression or phobias and a refusal of ECT for a diagnosis of 'irrationality' to be made: there also has to be evidence that the patient is not thinking clearly at all, or cannot give any reason for his decision. And 'in practice' it is extremely difficult to be sufficiently sure that the decision is really irrational and the treatment really will be beneficial except where the patient's life is in danger or (s)he is refusing basic necessities. The presumption should be against coercion and the patient considered 'rational until proved irrational'.

1) Before coming to the main dispute between Professor Sherlock and Drs Culver, Ferrell and Green whether it can be morally right to overrule the 'competently made [but] irrational decision' of a patient - we need to consider their shared definition of competence. This is that the patient 'knows he is ill, knows that the physician believes this treatment will help him and knows that he is being called upon to decide this question'. Although this definition draws the line more or less where one feels it should be drawn - including the normal patient as competent, and excluding the unconscious, drunk, insane and delirious -it requires two modifications. First, it would be better to say 'knows he has been diagnosed as ill', to cover the case where, as sometimes with mental illness, the very question as to whether the patient is ill at all is in dispute. Secondly, 'knows' needs to be interpreted as involving an imaginative rather than merely formal awareness - a child, in particular, can fulfil these requirements formally; but because he lacks any real sense of what will happen if he is or is not treated he is not really competent to make the decision.

2) Given this modified definition of competence, and accepting, as Professor Sherlock does, that normally the decision of a 'competent' patient should

\section{Key words}

Medical ethics; consent; autonomy; impaired autonomy; depression and consent; paternalism. be respected, is this still true of 'irrational' decisions? 'Irrational', obviously, has more than one meaning. In one sense, any decision which one is likely to regret, or likely eventually to be glad to have been prevented from taking, is irrational. But to permit the overruling of a competently made decision on these grounds alone would, for two reasons, give a doctor far too much power. First, it would interfere drastically with personal freedom; secondly, since the doctor's expertise covers only the medical considerations, while the patient has to take non-medical ones into account as well, his superior knowledge is not of a kind to enable him always to judge whether or not the patient is being irrational in this sense.

In any case, Professor Sherlock's notion of irrationality is much stronger: it adds to this, in effect, inability to give a reason for one's decision (this being distinguished from refusing to give a reason, or giving an eccentric one), plus the presence of a psychological condition, such as extreme depression, pathological indecisiveness, or phobia, which makes rational autonomous choice impossible, because it leaves a person with only the 'informational' and not the 'voluntariness' component of genuine competence: 'A person with insomnia, anorexia, anhedonia, psychomotor retardation, feelings of helplessness and hopelessness, etc, is simply not in a position to be autonomous in any recognisably valuable sense'. Under these conditions, to relieve a person's depression, even against his expressed wishes, is to increase his opportunity for happiness and his personal autonomy.

This definition of irrationality contains two elements - the inability to give a reason for one's decision, and the presence of a psychological condition interfering with voluntary choice - which Professor Sherlock does not distinguish, but which are different, and which must both be present for there to be irrationality. Inability to give a reason, in itself, may simply mean that the person has an inarticulate 'gut reaction' against the treatment, and prefers to trust this reaction rather than the expert evidence. To do this is, in a sense, irrational. But it has often happened - not only in medicine - that the calculations of the experts, even though based on good evidence, have been proved wrong, and the instinctive responses of the layman 
have been proved right. Given this real possibility that the patient may in fact be right to trust his 'gut response', his decision ought to be respected.

On the other hand, such conditions as phobias also do not in themselves render a refusal of treatment irrational. In itself, a phobia, like an external threat or inducement, merely alters the advantages and disadvantages of various choices: a patient with a phobia about a certain type of treatment can still rationally choose between 1 ) being treated and enduring the consequent mental anguish, 2) being treated first for the phobia, and 3) refusing treatment because of the suffering involved, all of which could be rational choices. (Similarly, 'a prisoner who is offered a pardon in exchange for participation in a potentially lethal experiment' is still free to make a rational choice either to risk his life in order to escape from prison or to stay in prison and be safe). Only if the phobia, or the depression or indecisiveness, is evidently preventing the patient from thinking clearly at all, or if it is combined with an inability to give any reason for his or her expressed preference, is one justified in regarding the preference - if it conflicts with medical opinion - as irrational. And so, the cases to be considered are those in which a 'minimally competent' patient refuses treatment which on the evidence is likely to be beneficial, can give no reason for his refusal, and, on other evidence, is so depressed, frightened, indecisive or lethargic that his capacity to choose seems seriously impaired. This range of cases is, I think, similar to Professor Sherlock's, but rather more limited.

3) Professor Sherlock believes that in all such cases a concern for the patient's welfare and personal autonomy justifies overruling his expressed preferences. However, these situations are by no means all alike. In many of them, it may be possible to avoid the whole problem either by finding an alternative treatment acceptable to the patient or by persuading, rather than forcing, him to be treated.

If, however, this is not an option, or has failed, there is then a different problem. This is that, given ordinary human ignorance, one cannot be absolutely certain that the proposed treatment will be beneficial. For example, the patient who refused ECT, saying 'nobody is going to put electricity in my brain' is seen by Professor Sherlock as making an irrational and phobic response, based on a misunderstanding of what ECT involves. This may well be so; but it is also possible that he is expressing, in a muddled way, a preference to trust his instinctive desire to avoid a form of treatment with unpredictable consequences. It seems to me that if the first is the case, overruling him could be justified; if the second, then, unless the evidence showed that success was certain and the risks nil, which is presumably impossible, his views should be respected.

So it seems that in practice one cannot say merely that when a patient irrationally refuses beneficial treatment one may ignore his wishes. One has rather to say that when there is sufficiently good evidence that the treatment will be beneficial and that the refusal is irrational, and where persuasion has failed and alternative treatment is not possible, to overrule the patient, will probably be right. There are some clear cases here, as when the patient's life is in danger if he is not treated, or when he is refusing such things as food, warmth, rest or cleanliness, and so almost certainly harming himself. But many other cases will be highly problematic, and it seems to be impossible to produce any general rule, except that the presumption ought presumably to be against overriding the patient's expressed wishes.

4) It should be noted that this whole discussion assumes that no considerations except the welfare and personal autonomy of the individual patient are involved. But there are often, in practice, institutional and legal requirements which alter the situation. The doctor may be legally forbidden to use coercion, even if he thinks it is morally right. Alternatively, he may be forced to use it, simply because of his obligations to other patients: if, for example, a patient in a mental hospital is suicidally depressed, and the only alternative to ECT, which will relieve the depression, is to have the patient continually watched by a member of the nursing staff, thereby diverting resources from other patients. Again, it would seem that all one can say is that the presumption should be against coercion, if it can reasonably be avoided.

\section{Summary}

By way of comment, I suggest:

1) That the definitions of 'competence' and 'rationality' require some modification.

2) That Professor Sherlock is right to argue that a competent but irrational decision to refuse beneficial treatment ought to be overruled; but in practice it is extremely difficult to be sufficiently sure that the decision is really irrational and the treatment really will be beneficial, except when the patient's life is in danger or he is refusing basic necessities.

3) That in practice the issue is further complicated by such questions as whether there are alternative treatments, whether persuasion is possible, what the doctor's or institution's legal obligations are, and what resources are available.

4) That the presumption should be against coercion, and the patient - however irritating this may be to some doctors - should be considered 'rational until proved irrational'.

\section{Acknowledgments}

A draft of this discussion was read at a conference of the Northern Association for Philosophy in January 1982 and to the Sociology of Medicine group at Manchester University in February 1982. I am grateful to members of both groups for their comments and in particular have incorporated suggestions from Professor Graham Bird (Philosophy, Manchester) and Dr John Clark (Psychology, Manchester), whose help I greatly appreciate. 